\title{
Novel modes in a Wilson-Cowan network
}

\author{
Jeremy Neuman ${ }^{1 *}$, Jack D Cowan ${ }^{2}$, Wim van Drongelen ${ }^{3}$ \\ From 24th Annual Computational Neuroscience Meeting: CNS*2015 \\ Prague, Czech Republic. 18-23 July 2015
}

Spontaneous [1] and synaptically-driven neural activity exhibit a wide variety of dynamics. In the latter case, recent experiments using spike-triggered LFPs [2] have been able to classify stimulated behavior into two distinct categories: 1) traveling waves with smooth attenuation when the input is weak; and, 2) localized responses when the impulse is strong. Unfortunately, our knowledge of the mechanisms behind these differences is lacking on both the cellular and network scales.

This study, employing the spatiotemporal mean-field Wilson-Cowan equations [3], provides a model for the nature of these two modes at the population level. Just as in [2], we detect damped traveling waves with exponential decay when the input is relatively small. When the stimulus increases, the activity stays localized as evidenced by the large slope in the peaks of the activity.

\section{Conclusions}

Understanding the contrast between traveling and localized activity in synaptically-driven neural networks is an important task due to its wide range of applications to areas such as vision, sleep and epilepsy. Here, it was shown that a
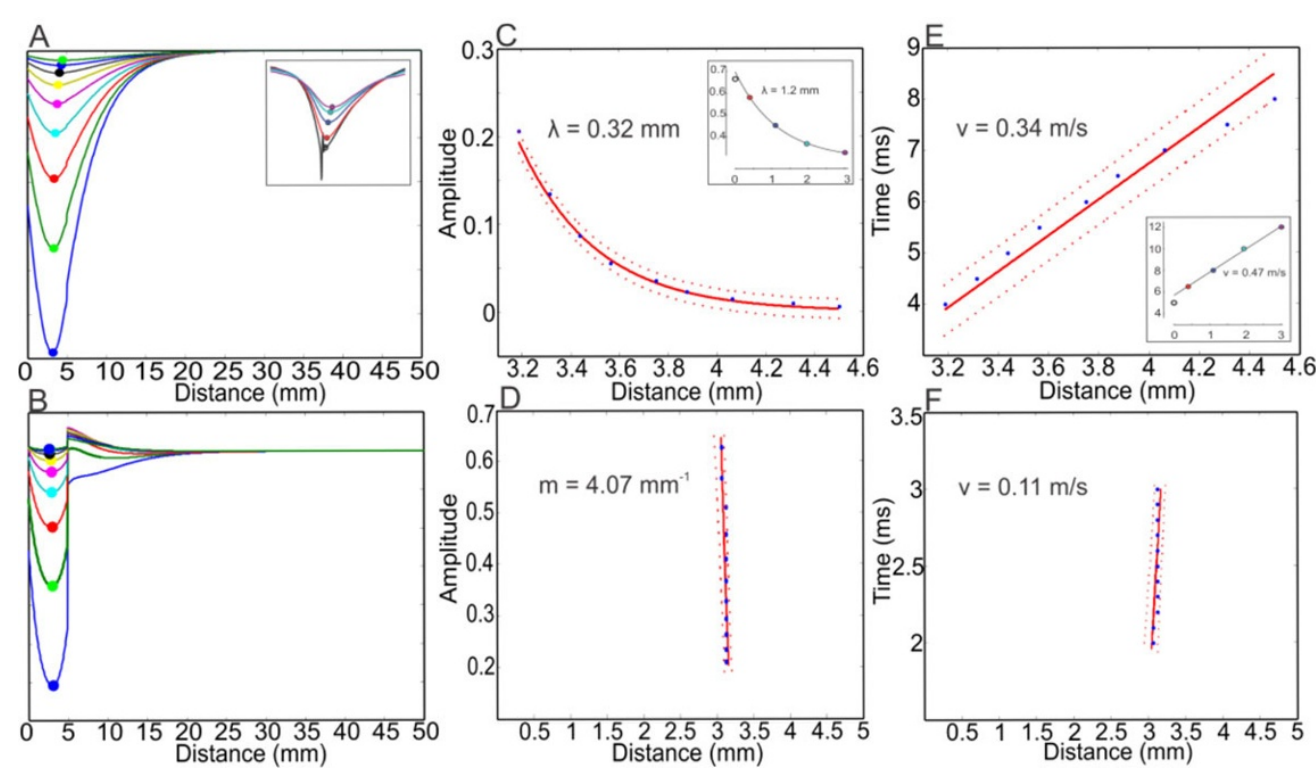

Figure 1 Simulations showing damped traveling waves and a localized response when the input strength is varied. (A-B) Diagrams of total activity at equally-spaced times. (C-D) Plots of distance traveled for the peaks (as percentage of global maximum) of curves in (A-B), respectively. (C) is fitted to an exponential as in [2] while (D) fits a linear curve with slope that can be approximated as infinity on the given scale. (E-F) Plots of the rate of propagation of the peaks in (A-B), respectively. Both fits are linear but the localized behavior moves at a much smaller speed. Insets are reproduced from [2].

\footnotetext{
* Correspondence: jneuman@uchicago.edu

${ }^{1}$ Dept. of Physics, University of Chicago, Chicago, IL 60637, USA

Full list of author information is available at the end of the article
} 
simple population model exhibits both modes of behavior. This result allows us to further study how various network properties such as density and connectivity strength give rise to these kinds of activity.

\section{Acknowledgement}

This work was supported by the Dr. Ralph and Marian Falk Medical Research Trust Fund.

\section{Authors' details}

'Dept. of Physics, University of Chicago, Chicago, IL 60637, USA. ${ }^{2}$ Dept. of Mathematics, University of Chicago, Chicago, IL 60637, USA. ${ }^{3}$ Dept. of

Pediatrics, University of Chicago, Chicago, IL 60637, USA.

Published: 18 December 2015

\section{References}

1. Mao B, Aronov D, Froemke R, Yuste R: Dynamics of Spontaneous Activity in Neocortical Slices. Neuron 2001, 32(6):883-898.

2. Nauhaus I, Busse L, Ringach D, Carandini M: Robustness of Traveling Waves in Ongoing Activity of Visual Cortex. J. Neuroscience 2012, 32(9):3088-3094.

3. Wilson $\mathrm{H}$, Cowan J: A mathematical theory of the functional dynamics of cortical and thalamic nervous tissue. Kybernetik 1973, 13(2):55-80.

doi:10.1186/1471-2202-16-S1-P271

Cite this article as: Neuman et al:: Novel modes in a Wilson-Cowan network. BMC Neuroscience 2015 16(Suppl 1):P271.

\section{Submit your next manuscript to BioMed Central} and take full advantage of:

- Convenient online submission

- Thorough peer review

- No space constraints or color figure charges

- Immediate publication on acceptance

- Inclusion in PubMed, CAS, Scopus and Google Scholar

- Research which is freely available for redistribution

Submit your manuscript at www.biomedcentral.com/submit 